ÉESTI NSV TEADUSTE AKADEEMIA TOIMETISED. GEOLOOGIÁ

ИЗВЕСТИЯ АҚАДЕМИИ НАУК ЭСТОНСКОП ССР. ГЕОЛОГИЯ

PROCEEDINGS OF THE ACADEMY OF SCIENCES OF THE ESTONIAN SSR. GEOLOGY

$1986,35,2$

УДК $551.794: 551.491 .4(474.2)$

Хельги КЕССЕЛ, Лейли СААРСЕ, Евгения ВИШНЕВСКАЯ

\title{
РАЗВИТИЕ ПРИБРЕЖНОГО ОЗЕРА КЯСМУ (СЕВЕРНАЯ ЭСТОНИЯ)
}

\section{Введение}

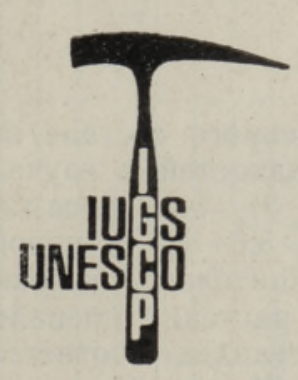

\section{Проект «Палео- гидрология»}

Проектом № 158 МПГК «Палеогидрологические изменения в умеренной зоне за последние 15000 лет» предусмотрено комплексное изучение озер с выделением типовых разрезов. В качестве вторичного типового озера, расположенного на террасе Лимниевого моря, можно считать изученное нами оз. Кясму, которое расположено на предглинтовой низменности, на одноименном полуострове в северной части Лахемааского национального парка (рис. 1). Геоморфология полуострова подробно изучена (Линкрус, 1971), но по палеолимнологии озера до последнего времени отсутствовали обоснованные данные.

Геологически изученное нами озеро небольшое, его площадь составляет 43 га, длина 1000 м, ширина 560 м, средняя глубина 2 м (Kask, 1964). Озеро овальное с малорасчлененной песчаной, в южной части торфянистой береговой линией. Питается оно атмосферными осадками, родниками и ручьем Тагаярве. Из озера вытекает ручей Сихитамми. Сейчас уровень воды в озере составляет 3,9 м н.у. м. (Mäemets, 1977). Озеро окружено сосновым лесом, в южной части его впадины наблюдаются заболоченные заросли. Площадь полей и лугов в районе водосбора незначительна из-за превалирования малопродуктивных подзолистых песчаных почв.

\section{Донные отложения}

Дно озера примерно на $80 \%$ покрыто сапропелем, мощность которого составляет $1-2$ м. Пробы для литологического, палинологического и диатомового анализов были взяты из расположенной в северо-западной части озера эталонной буровой скважины (рис. 1, скв. 5), где мощность озерных отложений наибо́льшая. Снизу вверх были вскрыты следующие отложения: лагунные пески (на глубине 5,9-6,0 м), лагунные алевриты с прослойками мелкозернистого песка и редкими остатками растений $(4,1-5,9$ м), лагунно-озерные сапропели, обогащенные до $70 \%$ терригенным компонентом $(3,7-4,1$ м), и типичные озерные сапропели $(2,4-3,7$ м $)$.

Химический состав изученных тонкодетритовых сапропелей следующий, \%: органического вещества $49-55, \mathrm{CaO} 1,7-2,0, \mathrm{MgO} 0,2-1,0$ и $\mathrm{CaCO}_{3} 3,6-6,3$ (рис. 2). Содержание органического вещества (OB) 
в алевритах $2-6 \%$, на отдельных уровнях до $11-16 \%$. Следует отметить, что алевриты бедны карбонатным компонентом, СаO в них содержится только $0,3-1,4 \%$, количество которого уступает даже его содержанию в сапропеле. MgO остается в пределах 0,8-1,8\%. Низкую карбонатность алевритов можно объяснить местоположением оз. Кясму на предглинтовой низменности, на выходе кембрийских глин и распространения малокарбонатных морен.

По данным рентгенодифрактометрического анализа в алевритах встречаются весьма характерные для данного района глинистые минералы - гидрослюды, каолинит, хлориты; в сапропеле - рентгеноаморфное ОВ, кварц, полевые шпаты и вышеназванные глинистые минералы.

Для выяснения характера изменений локальной растительности и стратиграфического расчленения донных отложений- оз. Кясму были проведены палинологические исследования $(\mathrm{X}$. Кессел). Экологическое состояние водоема и изменения за исследованный период выявлены диатомовым анализом (Е. Вишневская)

\section{Палинологическая характеристика}

На основе спорово-пыльцевого анализа и количественного состава зеленых водорослей Pediastrum boryanum и ее разновидностей, в изученном разрезе следует выделить три горизонта (рис. 3). Так, в самых

- базальных слоях, в I горизонте разреза на глубине 5,6-6,0 м преобладает пыльца сосны (до $80 \%$ ), наблюдается сравнительно высокое содержание пыльцы ольхи $(15 \%)$. Из травянистых растений превалируют Gímineae и Cyperaceae, пыльча которых составляет соответственно 5 и $2 \%$; пыльцы полыни Artemisia и маревых Chenopodiaceae меньше $1 \%$. Среди разнотравья в небольшом количестве встречаются представители Ranunculaceae, Rumex, Compositae, Rosaceae, Polypodiaceae, Filipendula, Rubiaceae и др. На основе небольшого количества пыльцы ели и ольхи можно полагать, что названный интервал разреза является переходным между палинозонами березы и ольхи (SA1) и верхней ели (SA2).

Спорово-пыльцевые спектры II горизонта (интервал 4,8-5,6 м) характеризуются повышенным содержанием пыльцы ели - $10-14 \%$. Пыльца сосны составляет $38-51 \%$, березы - $27-38 \%$, ольхи $5-10 \%$, широколиственных пород - 3-7\%. Присутствие пыльцы Carpinus, Acer и Fraxinus незначительно - ниже 2\%. Установлено, что содержание основных спор Polypodiaceae и Bryales в данных отложениях невелико, соответственно ниже 3 и $5 \%$. Взяв за основу споровопыльцевой состав, можно утверждать, что э́та часть разреза принадлежит к середине субатлантики или к палинозоне верхней ели (SA2).

Спектры III горизонта (интервал 2,4-4,8 м) отличаются высоким содержанием пыльцы сосны (до 60\%) и березы (до $37 \%$ ). Количество пыльцы ели уменьшается до $8 \%$. Пыльца широколиственных и лещины остается в пределах $5 \%$. Содержание пыльцы водных и прибрежноводных растений увеличивается до $5 \%$, преобладает пыльца злаковых. В составе спор встречаются зеленые мхи, многоножковые и хвощ. Снизу вверх по разрезу встречается пыльца водных растений - водокрас, частуха и ежеголовник. Эта часть разреза принадлежит к палинозоне сосны и березы (SA3).

Сравнение данной палинологической диаграммы с таковой в Северной Эстонии показывает, что она отличается относительно высоким фоном пыльцы сосны и древовидных берез, и низким - ели, дуба, липы и вяза на протяжении всей субатлантики. Интересно отметить, что в 


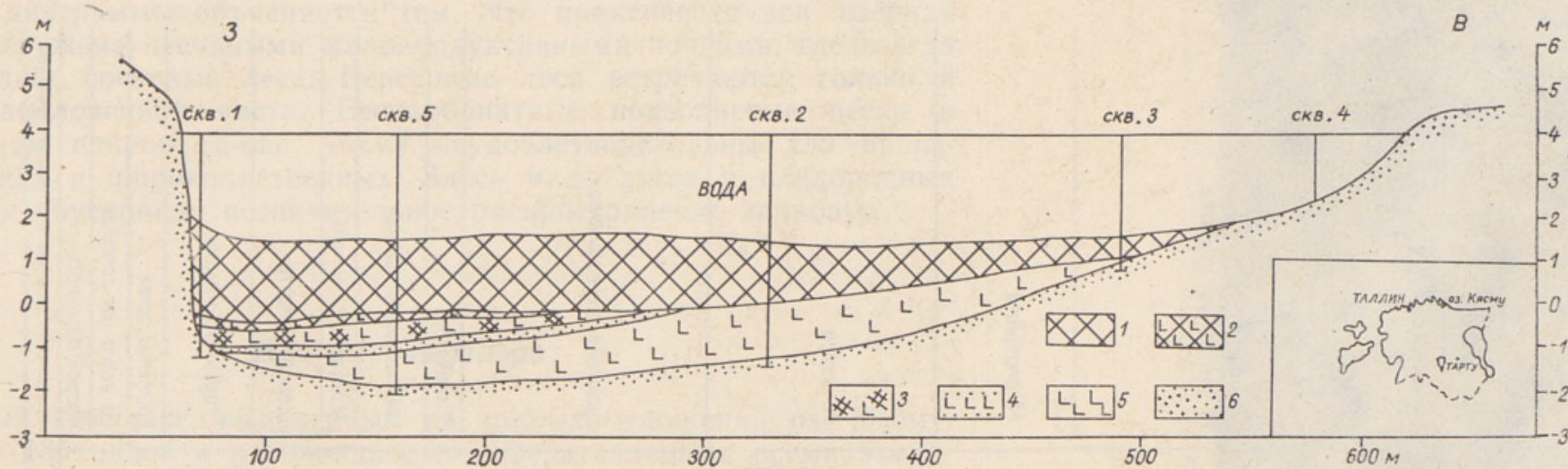

200

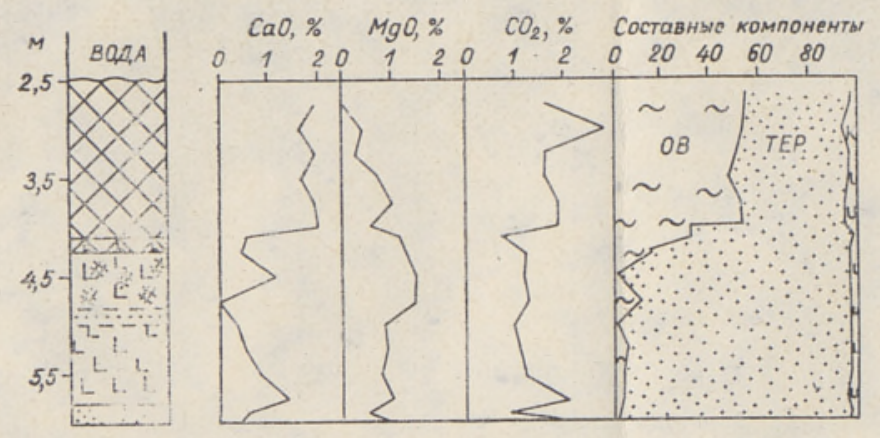

Рис. 2. Состав донных отложений оз. Кясму. ОВ - орга

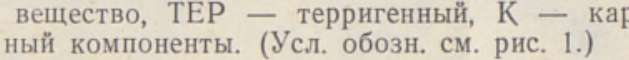

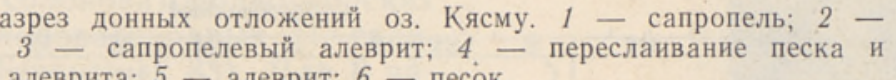

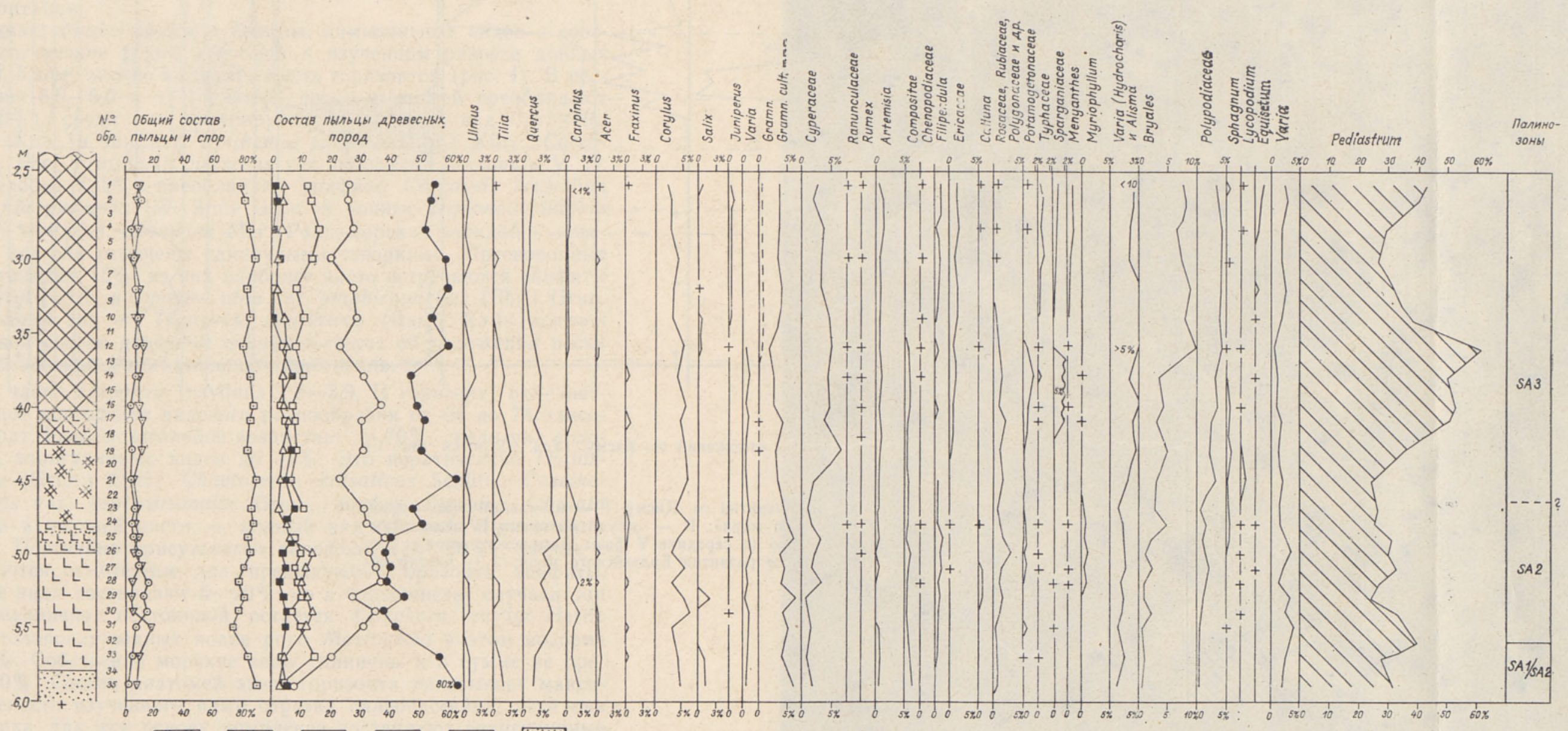

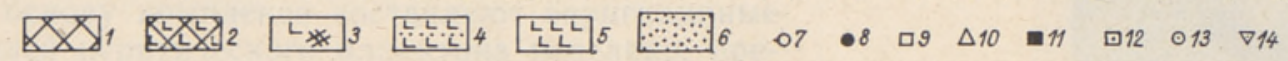

Рис. 3. Спорово-пыльцевая диаграмма донных отложений оз. Кясму (скв. 5). 1 - сапропель; 2 - алевритистый сапропель; 3 - сапропелевый алеврит; 4 - переслаивание песка и алеврита; 5 - алеврит; 6 - песок; 7 - пыльа березы; 8 - пыльца сосы; 9 - пыльда ольхи; 10 - пыльца ели; $11-$ пыльца широколиственных по- 

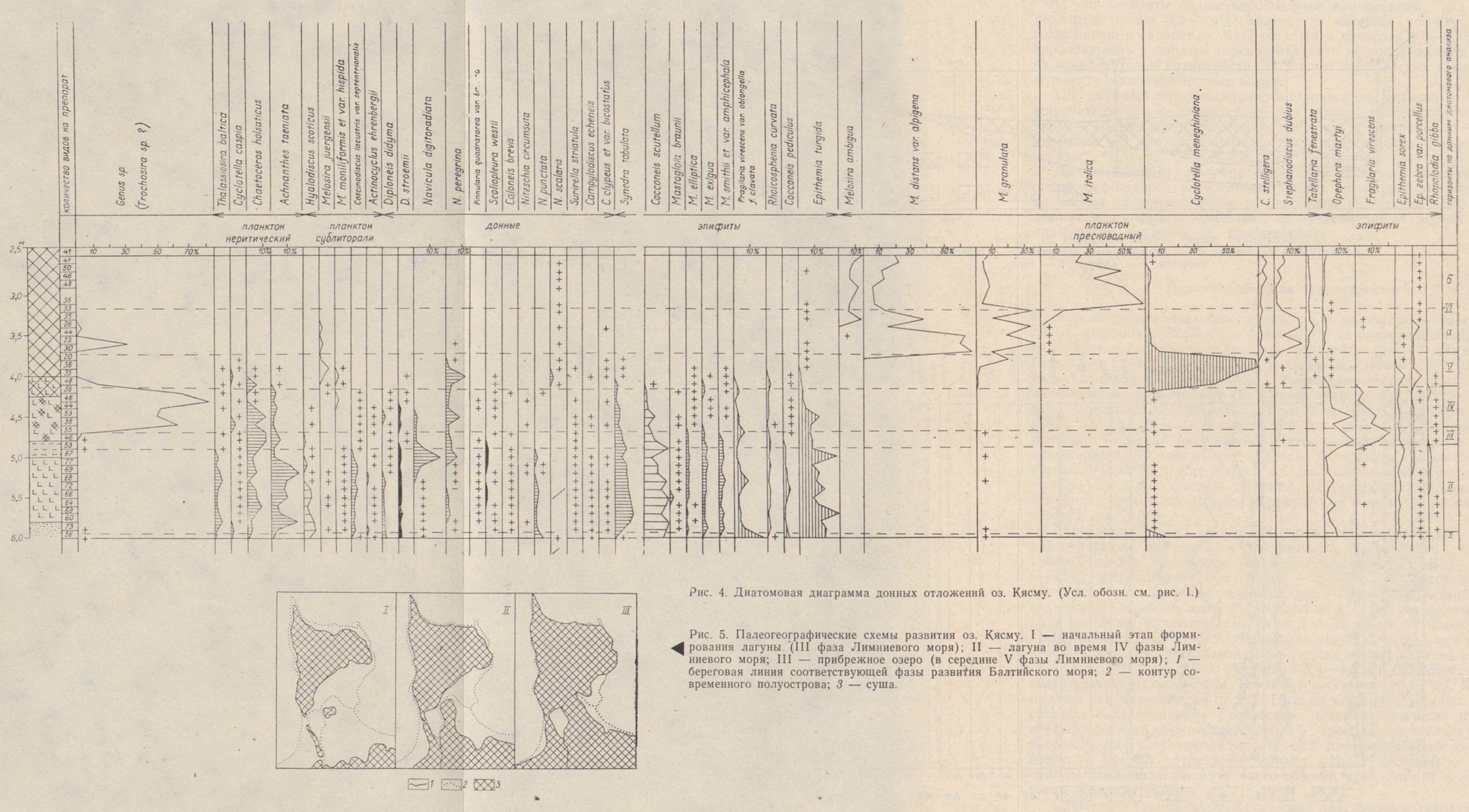

Рнс. 4. Диатомовая диаграмма донных отложений оз. Кясму. (Усл. обозн. см. рис. 1.)

Рис. 5. Палеогеографические схемы развития оз. Кясму. I - начальный этап формн-

нневого моря: III - пр фаза Лмен береговая линия соответствующей фазы развития Балтийского моря; 2 - контур современного полуострова; 3 - суша. 
верхней части сапропеля содержится мало пыльцы злаковых и полыни Характер диаграммы объясняется тем, что практически вся озерная впадина окружена песчаными малопродуктивными почвами, где всегда располагались сосновые леса. Березовые леса встречаются только в южной, заболоченной части. Бескарбонатные подзолистые пески в четвертичном покрове п-ова Кясму неудовлетворительны для произрастания ели и широколиственных. Здесь мало лугов и плодородных почв, что и обусловило незначительное распространение злаковых.

\section{Диатомовая флора}

Диатомовый комплекс, выделенный из донных отложений оз. Кясму. состоит из 186 видов и разновидностей, представленных всеми эколо гическими группами: морских эугалобов 27 , солоноватоводно-морских эугалобов 27, солоноватоводно-морских 12 , солоноватоводных 31 , галофилов 12, пресноводных 92 (галобов 9, индифферентных 83). Для 8 видов экология не установлена, так как нет единого мнения относительно их условий обитания.

На основании общего видового состава, доминантных видов и соотношения экологических групп диатомей в изученном разрезе донных отложений оз. Кясму можно выделить шесть горизонтов (рис. 4). В песках на глубине 5,9-6,0 м (I горизонт) среди диатомей преобладают галофилы $(50 \%)$; среди них доминирует литоральный вид Cyclotella meneghiniana Kütz. и эпифиты Epithemia turgida (Ehr.) Kütz., Coccэneis pediculus Ehr., Fragilaria virescens var. oblongella f. clavata V. H. Среди мезогалобов $(31 \%)$ преобладают эпифиты Cocconeis scutellum Ehr. и Nitzschia punctata (W. Sm.) Grun. и донные Diploneis didyma (Ehr.) Cl., D. smithii. f. rhombica Mer. Роль морских эугалобов невелика $-4 \%$, все они отмечены единичными створками. Пресноводные диатомеи составляют $15 \%$, из них наиболее часто встречаются эпифиты Opephora martyi Herib. и Synedra ulna var. amphirhynchus (Ehr.) Grun. Солоноватоводный вид - Terpsinoë americana (Bail.) Ralfs отмечен единично. Такой состав диатомей свидетельствует об отложении песка в условиях мелководья и значительного опреснения.

В нижней части алеврита (глубина 4,8-5,9, II горизонт) отмечается значительное повышение видового разнообразия от 64 до 74 таксонов на препарат. Роль мезогалобов возрастает до $70 \%$; среди них солоноватоводных эвригалинных видов до $43 \%$. Это неритические Thalassiosira baltica (Grun.) Ostf., Chaetoceros holsaticus Schütt., Coscinodiscus lacustris var. septentrionalis Grun., эпифит Synedra tabulata (Ag.) Kütz. и в верхней части - донный вид Navicula digitoradiata (Greg.) A. S. Постоянно присутствуют галофилы (15-20\%), вместе с ними встречаются отмеченные.для предыдущего горизонта эпифиты. Пресноводные виды составляют 5-20\%, но в большинстве случаев они встречаются единично, постоянной остается Opephora martyi Herib. Содержание солоноватоводных видов рода Mastogloia в этом водоеме составляет $6 \%$. Собственно морские виды единичны и в сумме не превышают 5-10\%. Состав диатомей этоғо горизонта показывает максимальную соленость изученного нами отрезка палеобассейна, хотя она все же невелика, так как основу комплекса составляют эвригалинные виды. Участие представителей неритического планктона невелико, преобладают представители эпифитов и донные виды, что указывает на отложение алевритов в лагуне.

В алевритовой толще с рассеянным ОВ (глубина 4,6-4,8 м, III горизонт) видовое разнообразие сохраняется (46-53 таксона на препа- 
рат). Преобладают солоноватоводные эвригалинные виды (до $32 \%$ ), среди них также постоянные виды из рода Mastogloia. Снижается роль морских эугалобов $(2 \%)$ и солоноватоводно-морских $(7 \%)$. Характерно увеличение (до $40 \%$ ) пресноводных видов, среди них эпифитов Fragilaria virescens Ralfs и Opephora martyi Herib. Состав диатомового комплекса указывает на значительное опреснение водоема.

В самой верхней части алеврита с рассеянным ОВ (глубина 4,1 4,6 м, IV горизонт) видовое разнообразие остается прежним (35-55 таксонов на препарат). Характерной особенностью данного горизонта является массовое развитие (до $80 \%$ ) рода Troschosira. В комплексе горизонта значение морских эугалобов и солоноватоводно-морских видов невелико (не более $5 \%$ ). До $15 \%$ составляют солоноватоводные и галофилы, значение собственно пресноводных уменьшается снизу вверх от 30 до 3-8\%. Присутствие и преобладание окончательно неопределенного вида затрудняет характеристику данного горизонта.

Следующий, V горизонт, выделяется в основании сапропеля на глубине $3,7-4,1$ м, руководящую роль здесь играют галофилы $(68 \%$, рис. 4). Доминирует литоральная Cyclotella meneghiana Kütz. Среди мезогалобов лишь солоноватоводные составляют $24 \%$, морские виды уменьшаются, составляя в верхней части горизонта менее $1 \%$. Отмечается подъем кривой пресноводных видов до $30 \%$. Общий состав диатомового комплекса претерпевает значительные изменения. Все это указывает уже на существующие лагунно-озерные условия.

В самой верхней части сапропеля (глубина $2,4-3,7$ м, VI горизонт) видовое разнообразие сохраняется (33-44 таксона на препарат). Господствующую группу этого горизонта составляют пресноводные диатомеи - $98 \%$, галофилы составляют не более $2 \%$. Почти во всех пробах единично отмечена солоноватоводная Nitzschia scalaris (Ehr.) W. Sm. Доминируют виды планктонного рода Melosira. По замещению руководящих форм выделяется два подгоризонта - VIa и VIб. В VIa на глубине $3,0-3,6$ м доминируют Melosira distans var. alpigena Grun., M. granulata (Ehr.) Ralfs и Stephanodiscus dubius (Fricke) Hust.; в VIб на глубине 2,4-3,0 м - Melosira italica (Ehr.) Kütz. и M. ambigua (Grun.) O. Müll. Состав диатомей соответствует комплексу типичного пресноводного озера.

\section{Выводы}

Состав диатомового комплекса позволил установить изменения в режиме водоема за период в течение осадконакопления исследованной толщи, выделить различные горизонты постепенного опреснения водоема и проследить в развитии прибрежного водоема все фазы, за исключением зачаточной лагуны. Пески в изученном разрезе на глубине $5,8-6,0$ м накопились в мелководной лагуне, которая формировалась здесь в палинозоне березы и ольхи, в конце III фазы Лимниевого моря. Весь комплекс алёвритов сформировался также в лагунных условиях (рис. 5). В отложениях этой лагуны был найден смешанный состав диатомей, в который входят все экологические группы, т. е. мезогалобы . с небольшим участием морских эугалобов и пресноводные, формировавшиеся в условиях сильно опресненной воды. Среди комплекса широкораспространенных видов имеются и холодноводные аркто- и северобореальные виды [Thalassiosira baltica (Grun.) Ostf., Chaetoceros holsaticus Schütt. и Achnanthes taeniata Grun.] в сумме не более 20\%. Биогеографический состав диатомей лагуны аналогичен составу диатомей соответствующих отложений Балтийского моря. Хотя изученные нами 
алевриты формировались во время существования Лимниевого моря, в них отмечены типичные литориновые формы: Terpsinö̈ americana (Bail.) Ralfs, Melosira moniliformis et var. hispida Castr., Navicula peregrina (Ehr.) Kütz., Nitzschia circumsuta (Bail.) Grun., N. scalaris (Ehr.) W. Sm., Suriella striatula Turp., Campylodiscus echeneis Ehr.

Вследствие постепенного неотектонического поднятия земной коры связь с морем постепенно ослабевала и в начале V фазы Лимниевого моря здесь сформировалось лагунное озеро (рис. 5). Пө палинологическим данным формирование лагунного озера соответствует ранней половине палинозоны сосны и березы. В этом лагунном озере начали осаждаться сапропели, а в воде его обитали галофилы (до 68\% ; рис. $4, \mathrm{~V}$ горизонт). Роль солоноватоводно-морских и солоноватоводных диатомей постепенно уменьшалась, морские виды диатомей встречаются единично. Если учесть возраст хронологических границ субатлантики (Каяк и др., 1976) и предположить, что скорость осадконакопления сапропеля была более или менее постоянной, можно установить, что лагунное озеро образовалось примерно 800 л. н. и существовало только в течение $160-200$ лет.

В самой верхней части субатлантики лагунное озеро постепенно преобразовалось в типичное пресное озеро, в котором накопился тонкодетритовый сапропель. Состав диатомей свидетельствует о полной изоляции водоема и о формировании прибрежного озера, уровень которого, по данным диатомового анализа, еще не стабилизировался. Так, более высокий уровень оз. Кясму наблюдается в первую половину SA3 (рис. 4, подгоризонт VIa), когда среди планктонных видов преобладает Melosira granulata (Ehr.) Ralfs, во вторую половину (подгоризонт VIб) возрастает роль.Melosira itatica (Ehr.) Kütz. Ведущая роль умеренно-теплолюбивых Melosira granulata (Ehr.) Ralfs и M. italica (Ehr.) Kütz. свидетельствует об эвтрофировании водоема и является показателем улучшения климатических условий.

\title{
Л ИТ Р РА Т Р А
}

Каяк К., Кессел Х., Лийвранд Э., Пиррус Р., Раукас А., Сарв А. Местная рабочая стратиграфическая схема четвертичных отложений Эстонии. - В кн.: Стратиграфия четвертичных отложений Прибалтики. Вильнюс, $1976,4-42$,

Линкрус Э. О геоморфологии полуострова Кясму. - Уч. зап. Тартуского гос. ун-та. Тр. по геогр. IX. Тарту, 1971, вып. 288, 3-30.

Kask, I. Eesti järvede nimestik. Tallinn, 1964.

Mäemets, A. Eesti järved ja nende kaitse. Tallinn, 1977.

\author{
Институт геологии \\ Академии наук Эстонской ССР

\begin{abstract}
Ленинградский государственный университет
\end{abstract}

Поступила в редакцию $7 /$ II 1985

Helgi KESSEL, Leili SAARSE, J. VISNEVSKAJA

\section{KÄSMU RANNAJÄRVE ARENG (PÖHJA-EESTI)}

Artiklis on käsitletud Käsmu järve kuhjunud setete lasumust, kooștịst, ștrațigraafiat ja diatomeefloorạt ning antud ülevaade järve arenguloost. 


\section{THE DEVELOPMENT OF THE COASTAL LAKE KÄSMU (NORTH-ESTONIA)}

Among the geologically investigated lakes, L. Käsmu on the Limnea Sea terrace at the elevation of $3.9 \mathrm{~m}$ meets the demands of a secondary reference site according to the IGCP Project $\mathrm{N}$ 158. The lake sediments consist of gyttja rich in terrigenous and poor in calcareous matter (Figs 1,2). They are underlain by lagoon silt and sand. Lithological, palynological and diatom studies have revealed that the lake and lagoon sediments with a maximum thickness of $3.6 \mathrm{~m}$ represent a sequence starting in the Early Subatlantic period (Fig. 3). The deposition of sandy and silty sediments took place during the III and IV phases of the Limnea Sea (LimIII, LimIV, Fig. 5), in a brackish basin. In the silty sediments all ecological groups of diatoms (from marine up to freshwater ones) have been established (Fig. 4). The lake was formed at the beginning of the phase V of the Limnea Sea (LimV, Fig. 5) which became finally isolated from the Baltic Sea. That event took place rather lately, in the middle of the phase V of the Limnea Sea, approximately 600 years B.P. At first the water level in that coastal lake stood relatively high, with Melosira granulata flourishing in it. During the second period the water level gradually lowered, and among the diatoms Melosira italica (Ehr.) Kütz. started to predominate. 